\title{
The Effects of Diabetes on Placental Lipase Activity in the Rat and Human
}

\author{
S. KAMINSKY, C. P. SIBLEY, M. MARESH, C. R. THOMAS, AND S. W. D'SOUZA \\ Departments of Child Health [S.K., C.P.S., S.W.D.] and Physiological Sciences [C.P.S.], University of \\ Manchester, Epithelial Membrane Research Centre, and Department of Obstetrics and Gynaecology [M.M.], \\ St. Mary's Hospital, Manchester, and Department of Medicine, St. Thomas's Hospital, \\ London, United Kingdom [C.R.T.]
}

\begin{abstract}
Lipase activities were measured at $\mathrm{pH} 4$ and pH 8 in the placentas of rats made diabetic by streptozotocin treatment and also in the placentas of women classified as having 1 ) impaired glucose tolerance or type 2 diabetes, 2) type 1 diabetes with no associated vascular complication, and 3 ) type 1 diabetes with associated vascular disease. In both sets of experiments, the placentas were compared with normal control groups. The placental lipase activity measured at $\mathrm{pH} 8$ was not significantly different in either streptozotocin-treated rats or impaired glucose tolerance/diabetic women as compared with controls, whereas the lipase activity measured at $\mathrm{pH} 4$ increased significantly as compared with controls in both species. Furthermore, in the women there was a significant correlation between placental lipase activity at $\mathrm{pH} 4$ and birth weight in impaired glucose tolerance/type 2 diabetes. It is suggested that the increased placental lipase activity may contribute to the increased fetal weight in human diabetic pregnancy, by contributing to the increased fat transfer across the placenta from mother to fetus. (Pediatr Res 30: 541-543, 1991)
\end{abstract}

Abbreviations

IGT, impaired glucose tolerance

Diabetes in pregnancy produces major changes in maternal plasma lipid concentrations (1-3). Plasma triglycerides are elevated in both type 2 diabetes and gestational diabetes, whereas in type 1 diabetic patients plasma triglycerides are not significantly elevated above the level associated with normal pregnancy (2). The hyperlipidemia of type 2 diabetic pregnancy leads to increased FFA passage across the placenta and may be associated with neonatal macrosomia (2). Furthermore, placentas from women and rats with severe diabetes have an increase in their triglyceride/DNA content ratio (3).

Placental lipases are thought to play a role in the transfer across the placenta of FFA derived from maternal VLDL (4). It has also been proposed that the placenta esterifies fatty acids crossing from the maternal circulation and temporarily stores the triglyceride. Intracellular lipases could then, when appropriate, hydrolyze this stored triglyceride, releasing FFA into the fetal circulation $(4,5)$.

There appear to be at least two distinct lipase activities in the placenta. One of the enzymes, assayed at $\mathrm{pH} \mathrm{8,} \mathrm{has} \mathrm{many} \mathrm{of} \mathrm{the}$

Received December 14, 1990; accepted July 16, 1991.

Correspondence: Dr. C. P. Sibley, Department of Child Health, St. Mary's Hospital, Hathersage Road, Manchester M13 OJH, UK.

Supported by grants from the North Western Regional Health Authority and the National Fund for Research into Crippling Diseases. properties of lipoprotein lipase $(6,7)$, whereas a second, measured at $\mathrm{pH} 4$, is probably lysosomal in origin (8).

Lipoprotein lipase activity in adipose tissue and diaphragm was found to be reduced in streptozotocin-induced diabetic rats, but in the same experiments the lipoprotein lipase-like activity in the placenta was unaffected $(9,10)$. However, Shafrir and coworkers $(4,9)$ showed that lipolytic activity in the placentas of diabetic rats was increased, and they inferred that this was due to an increase in placental "intracellular" lipase activity. Therefore, in the study reported here, we tested the hypothesis that placental $\mathrm{pH} 4$ lipase activity is increased in the placentas of diabetic women and rats. We have measured both the $\mathrm{pH} 8$ lipase and the $\mathrm{pH} 4$ lipase activity in the placentas of streptozotocin-induced diabetic rats and also in the placentas of mothers who were classified as having IGT or type 2 diabetes and those classified as having type 1 diabetes with or without vascular disease.

\section{MATERIALS AND METHODS}

Chemicals and isotopes. ${ }^{3} \mathrm{H}-9-10$ trioleyl glycerol (sp act $0.5-$ $1.0 \mathrm{Ci} / \mathrm{mmol}$ ) was purchased from Amersham International plc (Bucks, UK). Phosphatidylcholine, 9-10 trioleyl glycerol (99\%) glycerol, and BSA were all purchased from Sigma Chemical Company (Dorset, UK). Heat-inactivated horse serum was purchased from Flow Laboratories (Herts, UK). Streptozotocin was kindly provided by Dr. N. MacLeod (The UpJohn Co., Kalamazoo, MI). Other chemicals were ANALAR grade, purchased from BDH (Poole, UK).

Streptozotocin-induced diabetes in rats. Female CSE Wistar rats were made diabetic before mating by a single i.v. administration of $40 \mathrm{mg} / \mathrm{kg}$ of streptozotocin (11). Serum glucose was measured just before killing the animals on $\mathrm{d} 21$ of gestation $($ term $=22 \mathrm{~d})$. The fetuses and placentas were weighed, and the lipase activities at $\mathrm{pH} 4$ and 8 were determined. Mean values were calculated for each animal, and these litter mean values were used as the units for statistical analysis for all of the measurements.

Collection of placentas from diabetic pregnant women. Placentas were collected from diabetic women and women with IGT (12), all of whom were receiving treatment at St. Mary's Hospital, Manchester, UK. All of the women were at term (37-4l wk) except for one case with vascular disease, who was at $36 \mathrm{wk}$ gestation. The clinical details of the diabetic women are given in Table 1. Subjects in both diabetic and control groups were randomly chosen; we did not impose any exclusion criteria. The 22 placentas from the diabetic women were, for statistical analysis, first treated as one group and then treated as three subgroups [IGT/type 2 diabetes; type 1 diabetes without vascular disease, White's class B-D; type 1 diabetes with vascular disease, White's class $F / R(13)$ ]. We split the type 1 diabetes data in this way because White's class $F / R$ is associated with effects on birth 
Table 1. Clinical details of diabetic patients*

\begin{tabular}{lcccc}
\hline $\begin{array}{c}\text { Classi- } \\
\text { fication } \\
\text { of diabetes }(n)\end{array}$ & $\begin{array}{c}\text { BMI } \\
\left(\mathrm{kg} \cdot \mathrm{m}^{-2}\right) \dagger\end{array}$ & $\begin{array}{c}\text { HBA } \\
\text { range } \\
(\%)\end{array}$ & $\begin{array}{c}\text { Birth } \\
\text { wt }(\mathrm{g}) \dagger\end{array}$ & $\begin{array}{c}\text { Placental } \\
\text { wt }(\mathrm{g}) \dagger\end{array}$ \\
\hline IGT (7) & $31.0 \pm 6.6$ & $5.9-8.1$ & $4227 \pm 477$ & $728 \pm 50$ \\
Type 2 (4) & $38.3 \pm 7.2$ & $5.6-9.1$ & $4428 \pm 894$ & $970 \pm 254$ \\
Type 1 (7) & $28.8 \pm 4.2$ & $5.8-12.5$ & $3776 \pm 605$ & $667 \pm 160$ \\
Type 1 F/R (4) & $33.1 \pm 5.3$ & $6.2-10.4$ & $2660 \pm 911$ & $428 \pm 141$ \\
\hline
\end{tabular}

* BMI, body mass index; $\mathrm{HBA}_{1}$, glycosylated $\mathrm{Hb}$; IGT, impaired glucose tolerance; type 2, noninsulin-dependent diabetes; type 1, insulindependent diabetes; type $1 \mathrm{~F} / \mathrm{R}$, type 1 diabetes with nephropathy or retinopathy.

$\dagger$ Mean \pm SD.

weight (14); none of these patients had renal failure. The lipase activities measured at $\mathrm{pH} 4$ and 8 were compared with those in placentas from a randomly selected control group of normal mothers at term (37-41 wk).

Preparation of placentas and lipase assay. After removing the cord and fetal membranes, placentas were washed in saline and chopped into tiny fragments with a pair of scissors, and aliquots were homogenized in a Waring Blender in ice-cold $0.25 \mathrm{M}$ sucrose, $10 \mathrm{mM}$ Tris $\mathrm{HCl}$ buffer $(\mathrm{pH} 8)$ at a concentration of 20 $\mathrm{mg}$ tissue $\mathrm{mL}^{-1}$. The lipase assay, carried out at $\mathrm{pH} 4$ and $\mathrm{pH} 8$, was a modification of the method of Nilsson-Ehle and Schotz (15). The assay mixture $(0.1 \mathrm{~mL})$ contained (final concentrations) 9-10 trioleyl glycerol $(5.66 \mathrm{mM}$; ratio of unlabeled:labeled = $106: 1)$, phosphatidylcholine $(0.35 \mathrm{mM})$, glycerol $(8.5 \% \mathrm{wt} / \mathrm{vol})$, and BSA $(33.3 \mathrm{mg} / \mathrm{mL})$ in phosphate or citrate $/ \mathrm{KCl}$ buffer $(70$ $\mathrm{mM})$. In preliminary experiments we found that horse serum $(8.5 \% \mathrm{wt} / \mathrm{vol})$ added to the assay mixture inhibited enzyme activity at $\mathrm{pH} 4$ to $0.5 \pm 0.22 \%$ of control levels in rat $(n=5)$ and to $10 \pm 5.6 \%$ of control levels in human placentas $(n=5)$ but had no effect on activity at $\mathrm{pH} 8$ in rat or human placenta. Because $\mathrm{pH} 4$ activity in particular is very high compared with that at $\mathrm{pH} 8$ (see Results), horse serum (at a concentration of $8.5 \% \mathrm{wt} / \mathrm{vol}$ ) was added to the lipase assay at $\mathrm{pH} 8$ in all experiments described here to minimize any contribution from other lipolytic activities; no horse serum was present in lipase assays at $\mathrm{pH} 4$.

Blood glucose measurements. These were carried out by the glucose oxidase method. (Yellow Springs 23AM analyzer, Yellow Springs, $\mathrm{OH})$.

Statistical analysis. Data is shown as mean \pm SD with $n$ being the number of litters for the rat study and the number of placentas in the human study. The $t$ test (unpaired) was used to compare the data from normal (blood glucose 5-8 $\mathrm{mM}$ ) and diabetic (blood glucose $>10 \mathrm{mM}$ ) rats and to compare data from normal and IGT/diabetic patients. Linear regression analysis by the method of least squares was used to relate birth weight and placental lipase activity in the human study.

\section{RESULTS}

Streptozotocin-induced diabetic rats. After streptozotocin treatment mean blood glucose concentration for the streptozotocin group was $25.0 \pm 11.1 \mathrm{mM}(n=7)$ as compared with $6.0 \pm 0.2$ $\mathrm{mM}$ in the control group $(n=5)$. The resulting rat fetuses were smaller by $28 \%(p<0.05)$ as compared with a normal control group, but the placental weights were not significantly altered (Table 2).

The specific lipase activity in the placentas of streptozotocintreated rats measured at $\mathrm{pH} 4$ was $25 \%$ higher $(p<0.05)$ than controls, but the sp act at $\mathrm{pH} 8$ was not significantly different (Fig. 1).

Diabetic pregnant women. When the 22 placentas obtained from IGT/diabetic patients were analyzed as one group, the lipase activity at $\mathrm{pH} 4$ was $61 \%$ higher than in the control group $(p<0.01)$, whereas there was no difference in activity measured
Table 2. Fetal and placental weights of control and streptozotocin-treated rats (mean $\pm S D$ )

\begin{tabular}{lcc}
\hline & Control $(n=5)$ & $\begin{array}{c}\text { Streptozotocin- } \\
\text { treated }(n=7)\end{array}$ \\
\hline Fetal wt $(\mathrm{g})$ & $3.26 \pm 0.45$ & $2.35 \pm 0.69^{*}$ \\
Placental wt $(\mathrm{g})$ & $0.42 \pm 0.05$ & $0.38 \pm 0.05$ \\
\hline
\end{tabular}

$* p<0.05$ vs control, $t$ test (unpaired).

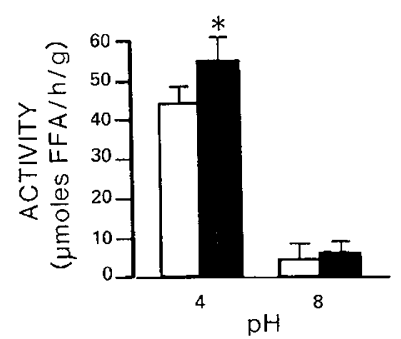

Fig. 1. Specific placental lipase activities at pH 4 and $\mathrm{pH} 8$ in control rats (open bars) and those with streptozotocin-induced diabetes (filled bars). Mean \pm SD for control $(n=5)$ and streptozotocin-treated $(n=7)$ rats. ${ }^{*}, p<0.05$ compared with control.

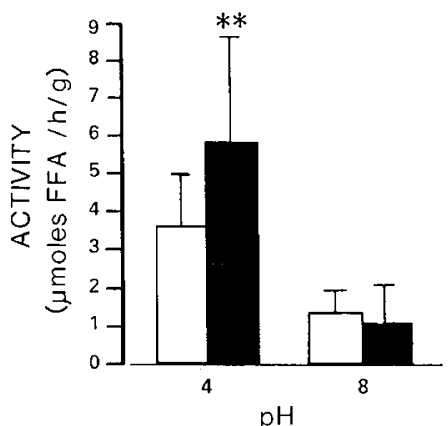

Fig. 2. Specific placental lipase activities at $\mathrm{pH} 4$ and $\mathrm{pH} 8$ in control women (open bars) and those with IGT or diabetes (filled bars). Mean $\pm \mathrm{SD}$ for control $(n=8)$ and IGT/diabetes $(n=22)$ women. ${ }^{* *}, p<$ 0.01 compared with control.

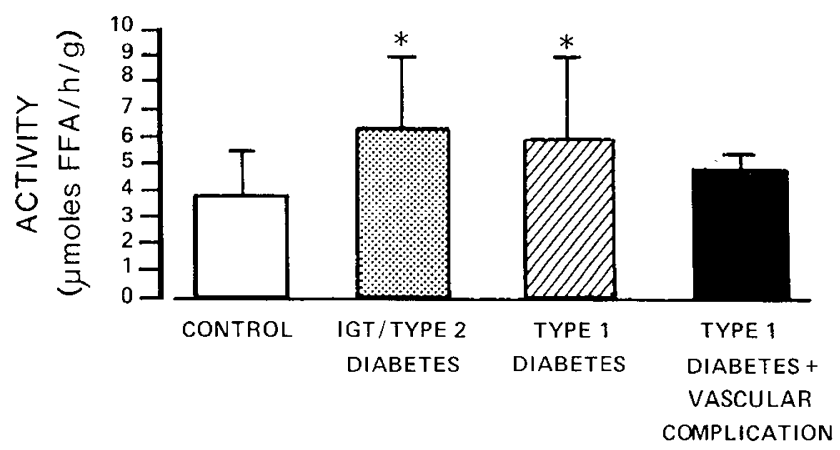

Fig. 3. Specific placental lipase activities (mean \pm SD) at pH 4 in control women ( $n=8$, as for Fig. 2 ), women with IGT or type 2 diabetes $(n=11)$, women with type 1 diabetes without vascular disease $(n=7)$, and women with type 1 diabetes with vascular disease $(n=4)$. ${ }^{*}, p<$ 0.05 compared with control.

at $\mathrm{pH} 8$ (Fig. 2). The data was then split into three subgroups: IGT/type 2 diabetes $(n=11)$, type 1 diabetes without vascular complication $(n=7)$, and type 1 diabetes with associated vascular disease $(n=4)$. The lipase activity measured at $\mathrm{pH} 4$ in the IGT/ type 2 diabetes and type 1 diabetes with no associated vascular complication groups was significantly greater than in the control group $(p<0.05)$ (Fig. 3). The lipase activity at $\mathrm{pH} 4$ in the type 1 diabetes group with associated vascular disease was not significantly different from that of the control group (Fig. 3). 


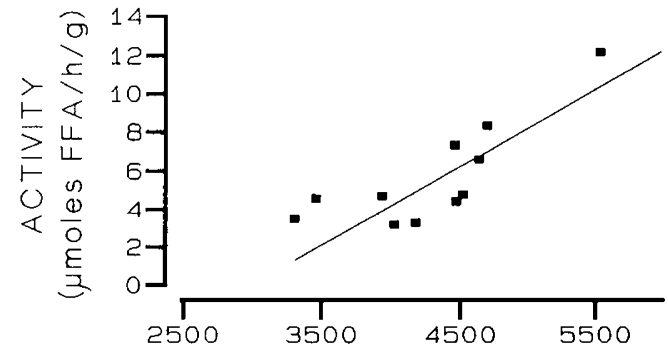

BIRTH WEIGHT (g)

Fig. 4. Linear regression of specific placental lipase activity at $\mathrm{pH} 4$ in women with IGT or type 2 diabetes against birth weight of their infants. Correlation coefficient of the regression line $=0.85, p<0.01$.

No difference in lipase activities measured at $\mathrm{pH} 8$ was observed between the diabetic subgroups and the control group (data not shown).

Linear regression analysis was carried out between placental lipase activity and birth weight for each of these diabetic subgroups. Only in the case of IGT/type 2 group was there a significant direct correlation with the $\mathrm{pH} 4$ lipase activity $[r=$ $0.85, p<0.01$ (Fig. 4)]; there was no correlation with type 1 diabetes even when the "with" and "without" vascular disease data groups were pooled.

\section{DISCUSSION}

The results of this study clearly show that maternal diabetes results in a marked increase in $\mathrm{pH} 4$ lipase sp act in both rat and human placentas. Lipase activity measured at $\mathrm{pH} 8$ in the placenta was unaffected by diabetes, consistent with previous studies $(4,9)$. This lack of effect at $\mathrm{pH} 8$ supports the view that placental lipoprotein lipase like activity is unperturbed by changes in maternal plasma lipid concentrations (4).

Shafrir and coworkers $(4,9)$ have suggested that FFA derived from maternal VLDL and fatty acids bound to maternal albumin are esterified to placental triglyceride and that intracellular lipases may then bring about release of FFA into the fetal circulation from this stored triglyceride. These authors (4) indirectly assessed "intracellular" lipase activity by incubating placental slices in a medium preloaded with esterified ${ }^{14} \mathrm{C}$-oleate containing BSA at pH 7.4 and measured the liberated ${ }^{14} \mathrm{C}$-oleic acid. They demonstrated a significant increase in the amount of ${ }^{14} \mathrm{C}$ FFA released into the medium when placentas from the streptozotocin-treated rats were incubated as compared with a nontreated group. They attributed this increase to intracellular lipase although they did not directly measure lipolytic activity of such an enzyme. The view of these authors that intracellular lipase has a role in fat transfer across the placenta is supported by our data. However, although the lipase activity measured here at $\mathrm{pH} 4$ may be intracellular, it may not be the same lipolytic activity referred to by Shafrir et al. (4), inasmuch as the pH of their assay was considerably higher.

Pregnant women with IGT or type 2 diabetes have higher circulating plasma triglyceride and FFA concentrations than those with type 1 diabetes (2). The birth weight of infants born to mothers with diabetes generally shows an increase over a normal population, although the reasons for this are not clearly understood. Although there appears to be a good relationship between maternal obesity and birth weight in IGT, there is little relationship between birth weight and the severity of the glucose impairment (16). In type 1 diabetes, there have also been many reports of excessive fetal growth in the presence of good diabetic control (17). This poor relationship is likely to be due to the influence of other factors such as insulin-like growth factors, although this has not so far been definitively demonstrated (18). Umbilical blood flow is likely to be impaired in type 1 diabetic patients with vascular disease (19), and this would obviously affect birth weight. Therefore, the most simple (although unproven at this stage) explanation for the correlation between birth weight and placental $\mathrm{pH} 4$ lipase activity in the IGT/type 2 group is that there is an association between placental and maternally derived lipid and birth weight. The lack of a relationship between birth weight and placental $\mathrm{pH} 4$ lipase activity in the type 1 group may be due to the complicating effects of growth factors and vascular disease on birth weight in these patients. Further studies are needed to elucidate this. In particular, maternal and fetal plasma as well as placental triglyceride and fatty acid concentrations need to be measured in conjunction with measurements of placental lipase activity in diabetic and normal subjects.

Finally, the importance of the correlation of $\mathrm{pH} 4$ placental lipase activity with birth weight reported here is strengthened by our other recent observation that the activity of this enzyme is reduced in the placentas of growth-retarded rat fetuses $(20)$.

Acknowledgment. The authors thank Jean French for her skilled secretarial assistance.

\section{REFERENCES}

1. Goldstein R, Levy E, Shafrir E 1985 Increased maternal fetal transport of fat in diabetes assessed by polyunsaturated fatty acid content in fetal lipids. Biol Neonate 47:343-349

2. Knopp RH, Montes A, Childs M, Mafuchi LJR 1981 Metabolic adjustments in normal and diabetic pregnancy. Clin Obstet Gynecol 24:21-49

3. Diamant YZ, Metzger BE, Freinkel N, Shafrir E 1982 Placental lipid and glycogen content in human and experimental diabetes mellitus. Am J Obstet Gynecol 144:5-11

4. Shafrir E, Barash V, Zederman R, Levy E, Goldstein R 1984 In: Shafrir E, Ronald AE (eds) Lessons from Animal Diabetes. Libby, London, pp 756766

5. Szabo AJ, DeLellis R, Grimaldi RD 1973 Triglyceride synthesis by human placenta. Am J Obstet Gynecol 115:257-262

6. Clegg RA 1981 Placental lipoprotein lipase activity in the rabbit, rat and sheep. Comp Biochem Physiol [B] 69:585-591

7. Rothwell JE, Elphick MC 1982 Lipoprotein lipase in human and guinea pig placenta. J Dev Physiol 4:153-159

8. Burton BK, Mueller HW 1980 Purification and properties of human placental acid lipase. Biochim Biophys Acta 618:449-460

9. Shafrir E, Barash V 1987 Placental function in maternal fetal fat transport in diabetes. Biol Neonate 51:102-112

10. Knopp RH, Warth MR, Charles D, Childs M, Li JR, Mabuelin H, Van Allen MI 1986 Lipoprotein metabolism in pregnancy, fat transport to the fetus and the effects of diabetes. Biol Neonate 50:297-317

11. Thomas CR, Eriksson G, Ericksson UJ 1990 Effects of maternal diabetes on placental transfer of glucose in rats. Diabetes 39:276-282

12. W.H.O. 1980 Expert Committee: Diabetes Mellitus Technical Report Series, 646.

13. White P 1965 Pregnancy and diabetes. Medical aspects. Med Clin North Am 49:1015-1024

14. Kitzmiller JL, Brown ER, Phillippe M, Stark AR, Acker D. Kaldany A, Singh S, Hare JW 1981 Diabetic nephropathy and perinatal outcome. Am J Obstet Gynecol:741-751

15. Nilsson-Ehle P, Schotz MC 1976 A stable radioactive substrate emulsion for assay of lipoprotein lipase. J Lipid Res:536-541

16. Maresh M, Beard RW, Bray CS, Elkeles RS, Wadsworth J 1989 Factors predisposing to and outcomes of gestational diabetes. Obstet Gynecol 74:342-346

17. Stubbs SM, Leslie RDG, John PN 1981 Fetal macrosomia and maternal diabetic control in pregnancy. Br Med J 282:439-440

18. Lind T, Whittaker PG 1989 The placenta as an endocrine regulator. In: Sharp F, Fraser RB, Milner RDG (eds) Fetal Growth. Royal College of Obstetricians and Gynaecologists, London, pp 53-67

19. Landon MB, Gabbe SG, Bruner JP, Ludmir J 1989 Doppler umbilical artery velocimetry in pregnancy complicated by insulin-dependent diabetes mellitus. Obstet Gynecol 73:961-965

20. Kaminsky S, D'Souza SW, Massey RF, Smart JL, Sibley CP 1991 Effects of maternal undernutrition and uterine artery ligation on placental lipase activities in the rat. Biol Neonate 60:201-206 